\title{
Natural clinical course of progressive supranuclear palsy in Chinese patients in Hong Kong
}

\author{
YF Shea *, Alex CK Shum, SC Lee, Patrick KC Chiu, KS Leung, YK Kwan, Francis CK Mok, Felix HW Chan
}

This article was published on 4 Dec 2019 at www.hkmj.org.

\section{A B S T R A C T}

Introduction: Progressive supranuclear palsy (PSP) is a common type of atypical parkinsonism. To the best of our knowledge, there has been no study of its natural clinical course among Chinese patients.

Methods: This retrospective study included 21 patients with PSP who had radiological evidence of midbrain atrophy (confirmed by magnetic resonance imaging) from the geriatrics clinics of Queen Mary Hospital and Tuen Mun Hospital. Clinical information was retrieved from clinical records, including age at onset, age at presentation, age at death, duration of symptoms, level of education, sex, presenting scores on Cantonese version of MiniMental State Examination, clinical symptoms, and history of levodopa or dopamine agonist intake and response. Clinical symptoms were clustered into the following categories and the dates of development of these symptoms were determined: motor symptoms, bulbar symptoms, cognitive symptoms, and others.

Results: Motor symptoms developed early in the clinical course of disease. Cox proportional hazards modelling showed that the number of episodes of pneumonia, time to vertical gaze palsy, and presence of pneumonia were predictive of mortality. Apathy, dysphagia, pneumonia, caregiver stress, and pressure injuries were predictive of mortality when analysed as time-dependent covariates. There was a significant negative correlation between the age at presentation and time to mortality from presentation (Pearson correlation $=-0.54, \mathrm{P}=0.04)$. Approximately $40 \%$ of caregivers complained of stress during the clinical course of disease.

Conclusion: Important clinical milestones, including the development of dysphagia, vertical gaze palsy, significant caregiver stress, pressure injuries, and pneumonia, may guide advanced care planning for patients with PSP.

\section{Hong Kong Med J 2019;25:444-52 https://doi.org/10.12809/hkmj198101}

${ }^{1}$ YF Shea *, FHKAM (Medicine), FHKCP

${ }^{2}$ ACK Shum, FHKAM (Medicine), FHKCP

${ }^{1} \mathrm{SC}$ Lee, BHS (Nursing)

PKC Chiu, FHKAM (Medicine), FHKCP

${ }^{2}$ KS Leung, FHKAM (Medicine), FHKCP

${ }^{2}$ YK Kwan, FHKAM (Medicine), FHKCP

${ }^{2}$ FCK Mok, FHKAM (Medicine), FHKCP

${ }^{2}$ FHW Chan, FHKAM (Medicine), FHKCP

1 Department of Medicine, Queen Mary Hospital, Pokfulam, Hong Kong

2 Department of Medicine and Geriatrics, Tuen Mun Hospital, Tuen Mun, Hong Kong

*Corresponding author: elphashea@gmail.com

New knowledge added by this study

Although this was a small cohort, $57 \%$ of patients with progressive supranuclear palsy (PSP) were initially misdiagnosed.

- Important clinical milestones, including the development of apathy, dysphagia, vertical gaze palsy, significant caregiver stress, pressure injuries, and pneumonia, were predictive of mortality in patients with PSP.

Implications for clinical practice or policy

- Monitoring of vertical gaze palsy or levodopa response is important throughout the clinical course of disease in patients with PSP.

- Important clinical milestones, including the development of dysphagia, vertical gaze palsy, significant caregiver stress, pressure injuries and pneumonia, may be used to guide the ideal timing for discussions of advanced care planning for patients with PSP.

\section{Introduction}

With the ageing of the Hong Kong population, clinicians must monitor increasing numbers of patients with neurodegenerative disease. Progressive supranuclear palsy (PSP) is a common form of atypical parkinsonism, ${ }^{1}$ with a prevalence of up to 18 cases per 100000 people. $^{1}$ Pathologically, PSP is characterised by the presence of neurofibrillary tangles, neuropil threads, or both in the basal ganglia and brainstem. ${ }^{1}$ In patients with classical Richardson's syndrome, the disease is characterised by early postural instability, falls, vertical gaze palsy, parkinsonism with poor response to levodopa, pseudobulbar palsy, and frontal release signs. ${ }^{2}$ 
Increasingly, patients with PSP have been reported to exhibit the following manifestations: parkinsonism, progressive gait freezing, corticobasal syndrome, apraxia of speech, frontal presentation, or cerebellar ataxia. ${ }^{2}$ Despite advancements in understanding the disease, there remains no approved treatment for PSP.

In addition to the need for accurate diagnosis of PSP, the natural clinical course of the disease is a concern for caregivers. ${ }^{3,4}$ Important problems for patients with PSP include increased risks of falls, dysphagia, aspiration pneumonia, pressure injuries, caregiver stress leading to institutionalisation, and long-term mortality. ${ }^{1}$ Given the lack of definitive treatment, it remains prudent for clinicians to educate caregivers regarding the natural course of PSP, which will ensure that caregivers are better prepared to care for their relatives; it will also allow implementation of different methods to avoid longterm complications, and may facilitate discussions of advanced care planning (ACP) at earlier stages of disease. ${ }^{3}$ In particular, clinicians need to identify the appropriate timing to discuss ACP. Previous studies have shown that the mean age at onset of PSP is 61 to 67.2 years, and that the disease affects both sexes equally; moreover, the median survival ranges from 5.3 to 10.2 years. $^{5}$ Factors predictive of mortality included age at onset, early clinical milestones (eg, falls, vertical gaze palsy, neck or limb stiffness, dysphagia, and incontinence), cognitive impairment, language impairment, autonomic dysfunction, male sex, and certain subtypes of PSP, such as classical Richardson's syndrome and pneumonia. ${ }^{6-16}$

To the best of our knowledge, there have been no studies of the natural clinical course of disease in Chinese patients with PSP. This information is important for clinical treatment and the design of future intervention studies (eg, for the purposes of sample size estimation). In the present study, we hypothesised that bulbar symptoms and pneumonia could predict mortality in patients with PSP. The aims of this study were (1) to calculate the prevalences of motor symptoms, cognitive symptoms, bulbar symptoms, other systemic symptoms, and long-term outcomes (eg, falls, tube feeding, pressure injuries, and institutionalisation) during the clinical course of PSP, and (2) to identify factors predictive of mortality among patients with PSP.

\section{Methods}

\section{Patients}

This retrospective study protocol was approved by the Institutional Review Board of the University of Hong Kong/Hospital Authority Hong Kong West Cluster (HKU/HA HKW IRB; Approval No. UW 17-483) and New Territories West Cluster Clinical and Research Ethics Committee (NTWC CREC; Approval

\section{香港進行性核上性麻瘦患者的自然臨床過程} 余日峯、岑俊強、李瑞貞、趙家俊、梁景成、關耀強、 莫俊強、陳漢威

引言：進行性核上性麻痺（PSP）是一種非典型帕金森病, 據我們所 知尚未有對華籍患者的自然臨床病程進行研究。

方法：這項回顧性研究納入 21 例PSP患者, 這些患者均來自瑪麗醫院 和屯門醫院的老年醫學診所, 在磁共振成像具有中腦萎縮的證據, 並從臨床記錄中檢索了臨床資料, 包括發病年齡、到診年齡、死亡 時的年齡、症狀的持續時間、教育程度、性別、簡短智能測驗 ( CMMSE）得分、臨床症狀以及對帕金森病的藥物（左旋多巴和多巴胺 作用劑）反應。症狀分為以下幾類：運動症狀、延髓症狀、認知症狀 等, 並確定這些症狀的發生日期。

結果：運動症狀在疾病的臨床過程中較早發展, Cox比例風險建模顯 示肺炎發作次數、垂直注視麻痺和肺炎可預測死亡率。時間相關的協 變量分析顯示冷漠、吞嚥困難、肺炎、照顧者壓力和裖瘡可預測死 亡。就診年齡與死亡時間之間存在顯著負相關（Pearson相關=-0.54， $\mathrm{P}=0.04$ ）。約 $40 \%$ 照顧者抱怨在照顧病人的過程中產生壓力。

結論：吞嚥困難、垂直凝視麻痺、照顧者明顯的壓力、裖瘡和肺炎是 重要的臨床情況與照顧者商討預設臨終照顧計劃。

No. NTWC/CREC/17127); the requirement for informed consent was waived by the review board. This study comprised a retrospective review of the clinical records of all patients who presented to the geriatrics clinics of Queen Mary Hospital and Tuen Mun Hospital between 1 January 2008 and 30 December 2017. All patients had at least 1 year of clinical follow-up and fulfilled the latest Movement Disorder Society Criteria for clinical diagnosis of $\mathrm{PSP}^{2}$ In addition, magnetic resonance imaging scans showed radiological evidence of midbrain atrophy (Hummingbird sign or Morning Glory sign) in all patients, according to radiological reports prepared by licensed radiologists. ${ }^{1}$ Twenty-five patients with clinically probable PSP and radiological evidence of midbrain atrophy were considered for inclusion in this study. Four patients were excluded because their clinical history and radiology findings were not suggestive of PSP. Finally, 21 patients were included: 19 had Richardson syndrome variant, one had PSP-corticobasal syndrome, and one had PSP with language impairment. The patient who had PSP with language impairment was previously described. ${ }^{17}$ Seven and 14 patients were recruited from Queen Mary Hospital and Tuen Mun Hospital, respectively.

\section{Baseline clinical information retrieved}

Clinical information was retrospectively retrieved from clinical records, including age at onset, age at presentation, age at death, duration of symptoms, level of education, sex, presenting scores on 
Cantonese version of Mini-Mental State Examination (C-MMSE), ${ }^{18}$ clinical symptoms, and history of levodopa or dopamine agonists intake or response. Clinical symptoms were clustered into the following categories: motor symptoms (including limb or neck stiffness, slowness of movement, balance impairment, gait impairment, falls, tremor, and vertical gaze palsy), bulbar symptoms (including dysarthria, dysphagia, and drooling), cognitive symptoms (including memory impairment, apathy, apraxia, dysexecutive syndrome, behavioural disinhibition, repetitive motor behaviour, hyperorality, and visual hallucination), and others (including faecal or urinary incontinence, constipation, insomnia, depression, and caregiver stress). ${ }^{6}$ The dates of development of the above symptom clusters were retrospectively determined.

'Age at presentation' was defined as the age at which the patient first presented to the geriatrics clinic. 'Duration of symptoms' was defined as the time between the first appearance of clinical symptoms of neurodegenerative disease and the first presentation. 'Age at onset' was defined as the difference between the 'age at presentation' and the 'duration of symptoms.' 'Disease duration' was defined as the difference between 'age at onset' and 'age at death' or the last date of follow-up. 'Time to diagnosis' was defined as the time between the date of disease onset and the date of diagnosis with PSP. The times to development of the above categories of symptoms were calculated in relation to both disease onset and presentation.

\section{Long-term outcomes}

Long-term outcomes were recorded, including falls, dysphagia, pneumonia, pressure sore development, and mortality. 'Time to event' was defined by the difference between the onset of clinical symptoms and first appearance of these long-term events. The time to each event from the time of first presentation was also calculated.

\section{Falls}

These were defined as events that resulted in the patient's body or body part inadvertently coming to rest on the ground or other surface lower than the body. The dates and numbers of falls were recorded. Geriatric day hospital training was recorded, including the pre-/post-training elderly mobility scale. ${ }^{19}$ Parkinsonism medications were often titrated in the geriatric day hospital.

\section{Pneumonia}

A diagnosis of pneumonia was made based on the following criteria: clinical signs and symptoms, white cell count of $\geq 10 \times 10^{9} / \mathrm{L}$ or proportion of neutrophils of $\geq 80 \%$, fever (body temperature of $\geq 37.6^{\circ} \mathrm{C}$ ), and new infiltrates or consolidations on chest radiography (X-ray or computed tomography). ${ }^{20}$ The dates and total numbers of pneumonia diagnoses were recorded.

\section{Dysphagia}

Any documentation of dysphagia by a speech therapist was recorded; alternatively (if available), reports of video fluoroscopic swallowing studies were obtained. Penetration was defined as the entry of barium material into the airway without passage below the vocal cords; aspiration was defined as the passage of barium material below the level of the vocal cords. ${ }^{21}$ The dates of diagnosis of dysphagia and tube feeding were recorded.

\section{Pressure injuries}

The locations of pressure injuries and their stages, according to National Pressure Ulcer Advisory Panel guidelines, were recorded. ${ }^{22}$ The dates of discovery of pressure injuries were recorded.

\section{Institutionalisation}

This was defined as institutionalisation of the patient, regardless of the level of care (eg, personal care facility or health care facility). The dates of institutionalisation were recorded where possible.

\section{Mortality}

The date and cause of death were recorded.

\section{Statistical analysis}

For descriptive statistics, continuous variables with normal distributions were expressed as means \pm standard deviations; variables that did not exhibit a normal distribution were expressed as medians (interquartile ranges). Symptom prevalences (cumulative incidences) were estimated using Kaplan-Meier method, with the first presentation defined as time zero. Patients who did not exhibit a particular symptom by the most recent assessment were censored at that point. Median times to clinical events were used as cut-offs to define 'early' or 'late' development of those events (binary classification). Time zero was consistently defined as the first clinical presentation or onset of disease, while the event time was defined as the number of months from first presentation or disease onset to occurrence of the event. Cox proportional hazards modelling was used to identify factors predictive of mortality based on the above binary classification or clinical events as time-dependent covariates. Pearson correlation coefficients were used to study the correlations between age at presentation and time to mortality (from the date of presentation). A two-tailed P value of $<0.05$ was considered statistically significant. All 
statistical analyses were performed using SPSS for Windows (version 24; IBM Corp, Armonk [NY], United States).

\section{Results}

\section{Basic demographics}

Twenty-one patients were included in this analysis, with a total of 1671.4 months of follow-up from onset (1428.4 months from presentation). The baseline demographics are summarised in Table 1 . The mean age of the patients at presentation was $67.6 \pm 9.4$ years, and most patients were men (76.2\%). Fifty-seven percent of the patients received another diagnosis at the time of presentation: nine patients were diagnosed with Parkinson's disease, one patient was diagnosed with Lewy body dementia, one patient was diagnosed with cervical myelopathy, and one patient was diagnosed with myasthenia gravis. None of the patients showed improvement when treated with levodopa or a dopamine agonist. Six patients $(28.6 \%)$ exhibited dementia at the time of presentation. Seventeen patients $(81 \%)$ had been referred to the geriatric day hospital for rehabilitation after a median of 20 months from presentation; they showed improvement in elderly mobility scale score (pre-geriatric day hospital elderly mobility scale score vs post-geriatric day hospital elderly mobility scale score: $14 \pm 4.6$ vs $16 \pm 4.3$, respectively, $\mathrm{P}=0.02$ ). Fifteen patients $(71.4 \%)$ died during follow-up with mean survival of $6.1 \pm 2.6$ years from onset $(5.2 \pm$ 3.2 years from presentation); 12 of these 15 patients (80\%) died of pneumonia, while two (13.3\%) died of sudden cardiac arrest.

\section{Clinical features}

Among the categories of potential symptoms, motor symptoms were most prevalent during initial presentation (specific symptoms affected up to $33.3 \%$ of patients) [Fig 1]. Motor manifestations were among the earliest clinical features observed in patients with PSP (online supplementary Appendix). The most frequent motor symptoms at the time of presentation were limb stiffness (33.3\%) and gait impairment (28.6\%). Vertical gaze palsy was present in $19 \%$ of patients at the time of presentation, but eventually affected all patients (100\%). The prevalence of gait impairment increased rapidly, such that $\geq 80 \%$ of the patients were affected within 3 years after presentation. All motor features showed increased in prevalence over time, with final prevalences ranging from $47.6 \%$ to $100 \%$. Regarding bulbar symptoms, dysarthria was the most frequent presenting symptom (9.5\%). Both dysarthria and dysphagia reached $100 \%$ prevalence over time (Fig $1)$.

Regarding cognitive symptoms, memory impairment and apathy were the two most frequent presenting symptoms, with prevalences of 33.3\% and $23.8 \%$, respectively (Fig 2). The respective prevalences of memory impairment and apathy increased to $>65 \%$ and $>45 \%$ over time. The prevalence of dysexecutive syndrome reached $28.6 \%$ during the clinical course of disease. Other cognitive symptoms relevant to patients with PSP showed lower prevalence, including apraxia, behavioural disinhibition, repetitive motor behaviour, hyperorality, and visual hallucination; the highest prevalence for any of these symptoms was 9.5\% throughout the clinical course of disease. The degree of caregiver stress also increased with progression of disease, such that it reached approximately $40 \%$ within 5 years after initial presentation.

Regarding systemic symptoms, faecal and urinary incontinence showed the highest prevalences (both reached approximately 40\%), particularly in the later stages of disease (Fig 2). Regarding long-term outcomes, the prevalences of aspiration pneumonia and dysphagia requiring Ryle's tube insertion both reached $100 \%$ over time (Fig 2 ).

\section{Factors predicting mortality}

Using median time to clinical events as cut-off (binary classification) [online supplementary Appendix] and with analysis in a Cox proportional hazards model, our results showed that earlier development of vertical gaze palsy (hazard ratio $[\mathrm{HR}]=4.4$, 95\% confidence interval $[\mathrm{CI}]=1.4-13.9, \quad \mathrm{P}=0.01)$ and

TABLE I. Basic demographics of Chinese patients with progressive supranuclear palsy in Hong Kong*

\begin{tabular}{|c|c|c|}
\hline Clinical characteristics $(n=21)$ & Findings & $\begin{array}{l}\text { Findings (range) } \\
\text { from previous } \\
\text { studies }^{1,2,5-17,23-28}\end{array}$ \\
\hline Age at presentation (y) & $67.6 \pm 9.4$ & $64.2-68.8$ \\
\hline Age at onset (y) & $66.6 \pm 8.7$ & $61-67.2$ \\
\hline Age at death (y) & $73.5 \pm 9.3$ & $69.6-73.8$ \\
\hline Female sex & $5(23.8 \%)$ & Equal sex distribution \\
\hline Baseline C-MMSE score & $23 \pm 4.7$ & - \\
\hline Duration of symptoms (y) & $1(0-1.5)$ & $2.3-3.7$ \\
\hline Years of education & $6.6 \pm 4.2$ & - \\
\hline Misdiagnosis & $12(57.1 \%)$ & - \\
\hline Time to diagnosis (from onset, y) & $3.4 \pm 2.4$ & $3-4.7$ \\
\hline Disease duration (from presentation, y) & $5.2 \pm 3.2$ & - \\
\hline Disease duration (from onset, y) & $6.1 \pm 2.6$ & $5.7-8.25$ \\
\hline Median survival from onset (y, 95\% Cl) & $6.9(4.1-9.6)$ & $5.3-10.2$ \\
\hline
\end{tabular}

Abbreviations: 95\% Cl = 95\% confidence interval; C-MMSE = Cantonese version of Mini-Mental State Examination

* Data are shown as mean \pm standard deviation, No. (\%) or median (interquartile range), unless otherwise indicated. Data from prior studies are shown as ranges 


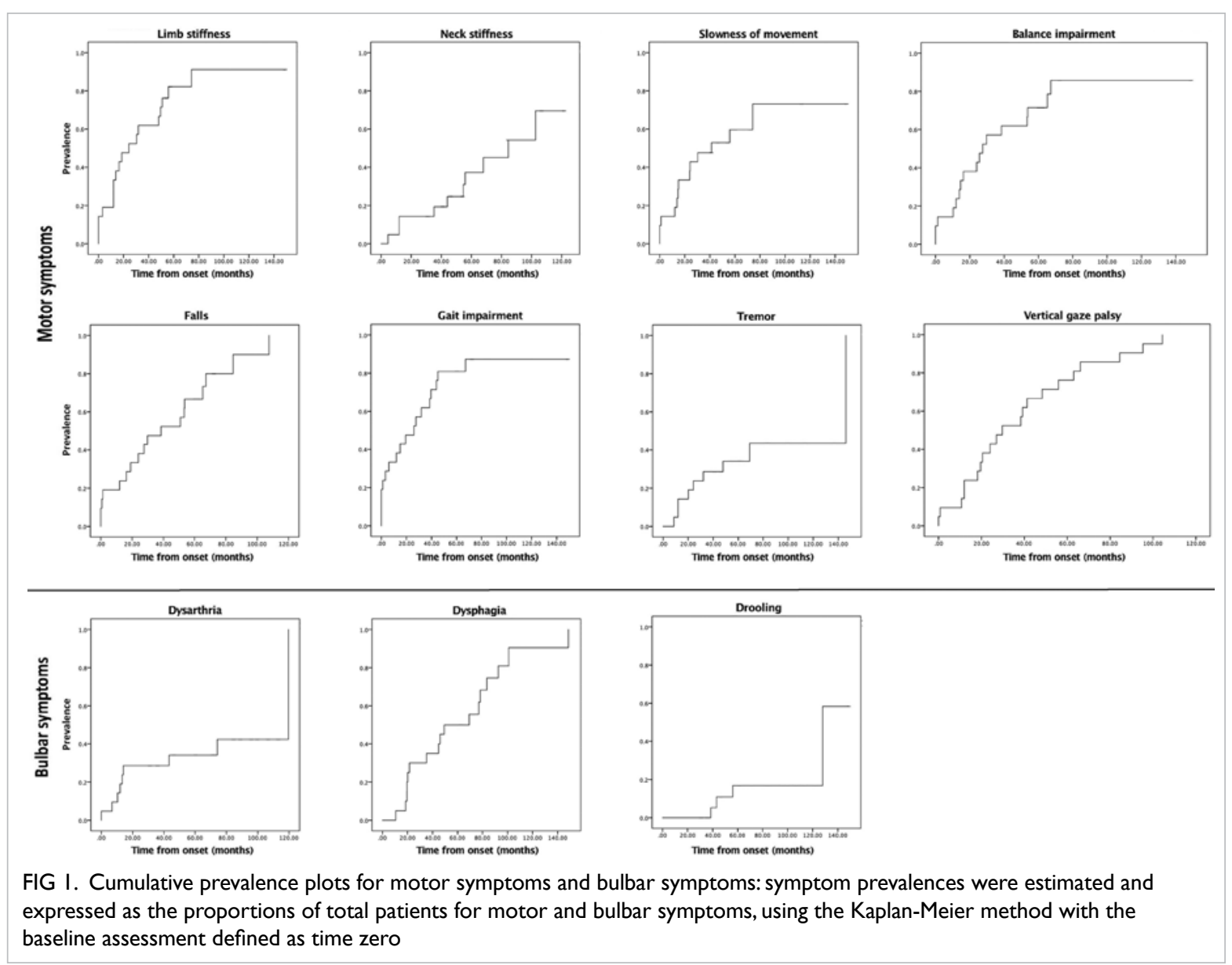

earlier development of pneumonia $(H R=10.9$, 95\% $\mathrm{CI}=2.2-53.3, \mathrm{P}=0.003)$ were predictive of mortality from disease onset (Table 2). Multivariate analysis showed that earlier development of vertical gaze palsy $(\mathrm{HR}=3.8, \quad 95 \% \quad \mathrm{CI}=1.1-13.0, \quad \mathrm{P}=0.04) \quad$ and earlier development of pneumonia $(\mathrm{HR}=10.4,95 \%$ $\mathrm{CI}=1.9-55.7, \mathrm{P}=0.006)$ were predictive of mortality from disease onset (Table 2). Earlier development of vertical gaze palsy $(\mathrm{HR}=3.3,95 \% \mathrm{CI}=1.1$ 10.5, $\mathrm{P}=0.01)$, earlier development of dysphagia $(\mathrm{HR}=3.7,95 \% \mathrm{CI}=1.0-12.9, \mathrm{P}=0.04)$, and earlier development of pneumonia $(\mathrm{HR}=10.6,95 \% \mathrm{CI}=2.2$ 52.0, $\mathrm{P}=0.004$ ) were predictive of mortality from disease presentation (Table 2). Multivariate analysis showed that only earlier development of pneumonia ( $\mathrm{HR}=9.9,95 \% \mathrm{CI}=1.9-51.8, \mathrm{P}=0.007)$ was predictive of mortality from presentation (Table 2 ). The number of episodes of pneumonia was also predictive of mortality in patients with PSP, indicating that pneumonia is a major cause of mortality (Table 2). There was a significant negative correlation between the age at presentation and time to mortality from presentation (Pearson correlation $=-0.54, \mathrm{P}=0.04$ ).

Using clinical events as time-dependent covariates in Cox modelling for prediction of mortality, we found that apathy, dysphagia, Ryle's tube feeding, pneumonia, and pressure injuries were predictive of mortality from both disease onset and presentation (Table 3). Caregiver stress was only predictive of mortality from presentation (Table 3).

\section{Discussion}

An accurate diagnosis of PSP is important for management of the disease in affected patients. However, only $43 \%$ of the patients in this study received a correct diagnosis at the time of initial presentation. This is potentially because vertical gaze palsy was not present initially and only developed during clinical follow-up (median time to develop, 19.6 months; online Supplementary Appendix). In addition, $43 \%$ of patients were initially misdiagnosed with Parkinson's disease; this group of patients may have had PSP with parkinsonism. ${ }^{2}$ Clinicians should regularly assess patients with parkinsonism for the presence of any vertical gaze palsy or poor response to levodopa, in order to correctly identify patients with PSP. Our reported mean time to diagnosis of 3 years was similar to the duration reported in previous studies (mean, 3.1-4 years). ${ }^{1,2,5-17,23-28}$ 


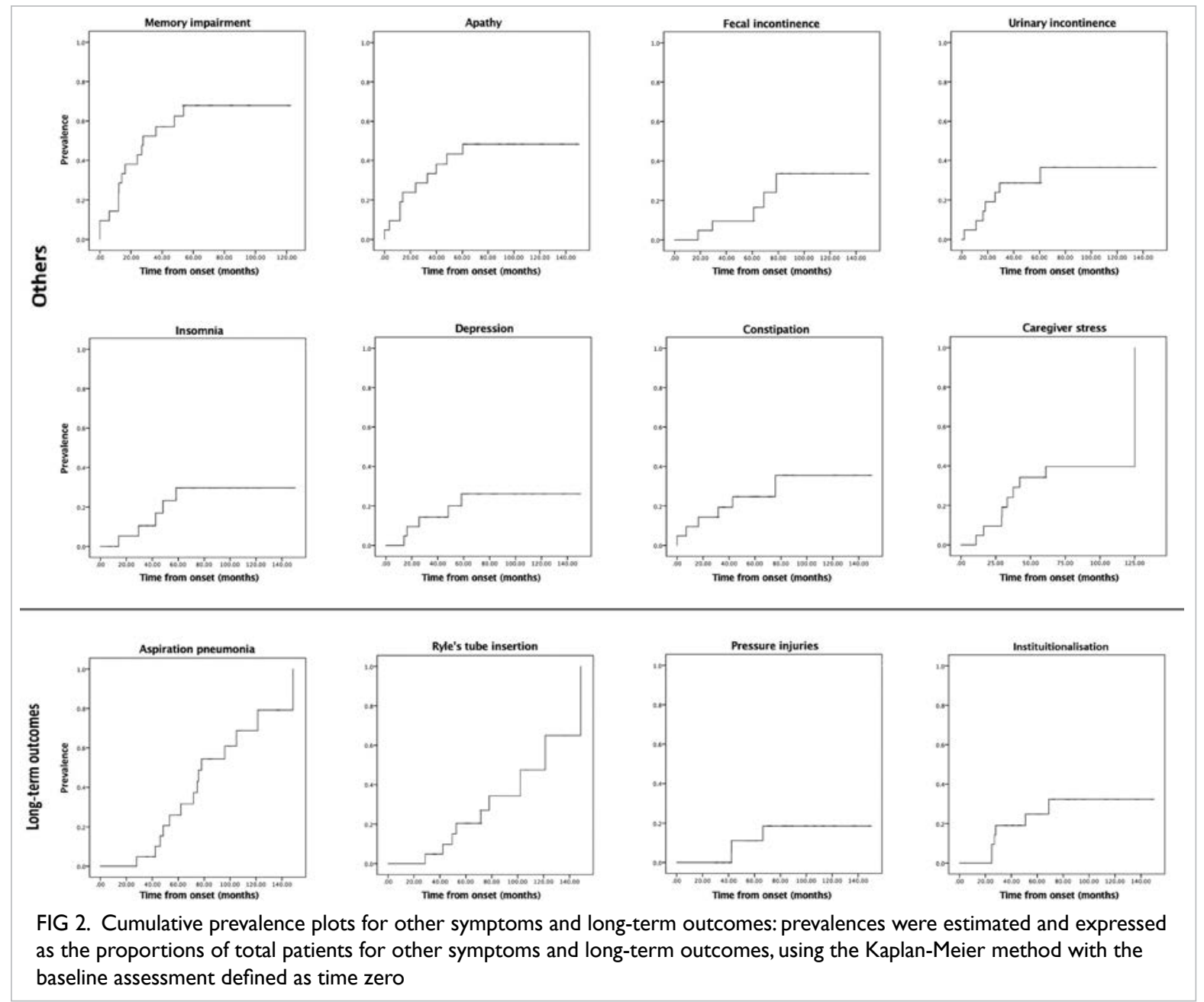

TABLE 2. Results of Cox modelling for prediction of mortality using median times to specific clinical events as cut-offs

\begin{tabular}{|c|c|c|c|}
\hline Clinical features & HR & $95 \% \mathrm{Cl}$ & $P$ value \\
\hline \multicolumn{4}{|l|}{ Predicting mortality from disease onset ${ }^{\star}$} \\
\hline \multicolumn{4}{|l|}{ Univariate } \\
\hline Time to vertical gaze palsy $<2.5$ years & 4.4 & $1.4-13.9$ & 0.01 \\
\hline Time to pneumonia $<6.5$ years & 10.9 & $2.2-53.3$ & 0.003 \\
\hline No. of pneumonia episodes & 1.9 & $1.1-3.2$ & 0.02 \\
\hline \multicolumn{4}{|l|}{ Multivariate } \\
\hline Time to vertical gaze palsy $<2.5$ years & 3.8 & $1.1-13.0$ & 0.04 \\
\hline Time to pneumonia $<6.5$ years & 10.4 & $1.9-55.7$ & 0.006 \\
\hline \multicolumn{4}{|c|}{ Predicting mortality from presentation of the patients ${ }^{\star}$} \\
\hline \multicolumn{4}{|l|}{ Univariate } \\
\hline Time to vertical gaze palsy $<1.6$ years & 3.3 & $1.1-10.5$ & 0.01 \\
\hline Time to dysphagia $<3.7$ years & 3.7 & $1.0-12.9$ & 0.04 \\
\hline Time to pneumonia $<6.5$ years & 10.6 & $2.2-52.0$ & 0.004 \\
\hline No. of pneumonia episodes & 2.17 & $1.2-3.9$ & 0.008 \\
\hline \multicolumn{4}{|l|}{ Multivariate } \\
\hline Time to vertical gaze palsy $<1.6$ years & 2.7 & $0.8-9.3$ & 0.1 \\
\hline Time to pneumonia $<6.5$ years & 9.9 & $1.9-51.8$ & 0.007 \\
\hline
\end{tabular}

Abbreviations: $95 \% \mathrm{Cl}=95 \%$ confidence interval; $\mathrm{HR}=$ hazard ratio

* Ages at onset/presentation, sex, and baseline Mini-Mental State Examination scores were not predictive of mortality 
TABLE 3. Results of Cox modelling for prediction of mortality using clinical events as time-dependent covariates

\begin{tabular}{|lcc|}
\hline Clinical events & HR (95\% Cl) & P value \\
\hline Prediction of mortality from disease onset & & \\
\hline Apathy & $3.2(1.1-9.7)$ & 0.04 \\
\hline Caregiver stress & $2.9(1.0-8.6)$ & 0.05 \\
\hline Ryle's tube feeding & $15.9(3.5-71.0)$ & $<0.001$ \\
\hline Dysphagia & $3.4(1.02-11.1)$ & 0.046 \\
\hline Pneumonia & $82.6(10.1-671.4)$ & $<0.001$ \\
\hline Pressure injuries & $5.3(1.3-21.7)$ & 0.02 \\
\hline Prediction of mortality from the time of & & \\
presentation & $3.3(1.1-9.9)$ & 0.04 \\
\hline Apathy & $3.6(1.2-10.8)$ & 0.03 \\
\hline Caregiver stress & $18.6(2.1-166.8)$ & 0.009 \\
\hline Ryle's tube feeding & $3.8(1.1-13.0)$ & 0.03 \\
\hline Dysphagia & $43.3(9.0-208.1)$ & $<0.001$ \\
\hline Pneumonia & $12.2(2.4-62.3)$ & 0.003 \\
\hline Pressure injuries & & \\
\hline
\end{tabular}

Abbreviations: $95 \% \mathrm{Cl}=95 \%$ confidence interval; $\mathrm{HR}=$ hazard ratio

TABLE 4. Recommendations for the management of disease in patients with progressive supranuclear palsy

Important symptoms to be addressed during the clinical course of disease

- Falls: consider comprehensive fall assessment with referral to geriatrics day hospital

- Rigidity: consider treatment with levodopa

- Dysphagia: evaluate clinical alertness with early referral to speech therapist for proactive assessment

- Vertical gaze palsy: consider usage of prism or audiobooks

- Drooling: encourage patients to swallow; consider usage of topical atropine eye drops $0.1 \% 1-2$ drops up to 4 times per day sublingually or botulinum toxin injection into submandibular or parotid glands

- Apathy: consider correction of sensory deficits including usage of hearing aids and eyeglasses

Important milestones to consider in discussions of advanced care planning

- Development of dysphagia

- Development of vertical gaze palsy

- Presence of significant caregiver stress

- Development of pressure injuries

- Development of pneumonia presentation. Patients with PSP should be referred to a physiotherapist and an occupational therapist for fall assessment, as well as guidance regarding the potential need for walking aids. Relatives should be educated to ensure close monitoring of environmental risks for falls. The patients in our cohort showed relatively early development of memory problems at a median duration of 9 months, which contrasted with the mean duration of 12 months observed in another study. ${ }^{6}$ There may have been bias in the current cohort, which recruited patients with PSP from a geriatrics clinic whereas the patients in the previous study were recruited from a neurology clinic. ${ }^{6}$

A previous meta-analysis showed mixed results with regard to whether the age at onset of PSP was predictive of mortality. ${ }^{5}$ Pooled results from six studies showed no prognostic effect of yearly increases in age at disease onset in either univariate or multivariate analyses. ${ }^{5}$ However, pooled results from nine studies using median age at onset as cut-off showed a pooled HR of 1.75 (95\% CI=1.32-2.32) in multivariate analysis. ${ }^{5}$ Other predictors of mortality found in the present study, including vertical gaze palsy, dysphagia, pneumonia, or pressure injuries, were previously reported in other studies. ${ }^{6-16} \mathrm{It}$ remains unknown whether resolution of dysphagia in patients with PSP can prevent pneumonia and reduce mortality. It is important for clinicians to refer patients with PSP involving dysphagia to a speech therapist for advice regarding food texture and appropriate swallowing posture (ie, chin-tuck) [Table 4]. ${ }^{29}$ During the clinical course of disease, approximately $40 \%$ of primary caregivers complained of caregiver stress, which was also determined to be a significant predictor of mortality. Patient aggression and depression have been reported as sources of stress. ${ }^{4}$ When these positive predictors of mortality appear, clinicians should consider discussing ACP with patients or caregivers (Table 4).

The finding of apathy as a time-dependent covariate for prediction of mortality is notable. Recently, apathy was found to predict survival in a cohort of 124 patients with syndromes associated with frontotemporal lobar degeneration (including 35 patients with PSP, mean age of $72.2 \pm 8.5$ years). ${ }^{30}$ The development of apathy in patients with PSP was related to brainstem, midbrain, and frontal atrophy. ${ }^{30}$ It remains unknown whether apathy accelerates the decline to death or indirectly signifies the degree of brainstem degeneration, including the development of dysphagia, which is also related to greater mortality. Future clinical trials may consider the use of therapeutic measures to address apathy, in order to assess their impacts on the survival of patients with PSP.

Because there is currently no disease-modifying treatment for patients with PSP, ACP is an important component of clinical care, for which patients and 
their caregivers can reach a consensus during the clinical course of disease. ${ }^{4}$ In addition, symptomatic care plays an important role. Symptoms relevant to patients with PSP include dystonia, drooling, gaze palsy (also known as reduced blinking), constipation, and apathy. ${ }^{4}$ Drooling could be managed by the administration of sublingual atropine drops (Table 4). ${ }^{4}$ Reduced blinking could be managed by frequent application of lubricating eyedrops. Gaze palsy could be managed by the use of prisms or audiobooks (Table 4). ${ }^{4}$ Apathy could be minimised by addressing sensory deficits, such as through the use of eyeglasses or hearing aids (Table 4 ). ${ }^{4} \mathrm{Up}$ to $75 \%$ of patients with PSP could be discharged home after stabilisation of symptoms. ${ }^{4}$

There are multiple limitations in the current study. First, it was a retrospective study involving reviews of clinical charts, and may be biased due to inconsistent documentation of symptoms. Second, there was a limited number of patients included, none of whom had autopsy and pathological confirmation of their diagnosis; however, we had radiological evidence of PSP. Third, our descriptive statistical results should be regarded as preliminary findings; only limited variables could be included in our Cox proportional hazards modelling for survival analysis. Notably, no specific scales were used to assess the severity of parkinsonism or other symptoms, including response to levodopa; most of our evaluations were subjective. Sequential C-MMSE scores were not recorded; thus, we were unable to examine the development of dementia over time. Fourth, we only included patients attending the geriatrics clinic; therefore, our cohort may not be fully representative of patients with PSP who present to most neurology clinics. Finally, the limited numbers of patients precluded stratified analyses based on subtypes of PSP.

In conclusion, important clinical milestones, including the development of dysphagia, vertical gaze palsy, significant caregiver stress, pressure injuries, and pneumonia, may be used to guide the ideal timing for discussions of ACP for patients with PSP, in order to facilitate long-term care.

\section{Author contributions}

All authors had full access to the data, contributed to the study, approved the final version for publication, and take responsibility for its accuracy and integrity.

Concept or design: YF Shea, ACK Shum.

Acquisition of data: YF Shea, ACK Shum.

Analysis or interpretation of data: All authors.

Drafting of the article: YF Shea, ACK Shum.

Critical revision for important intellectual content: All authors.

\section{Conflicts of interest}

The authors have no conflicts of interest to disclose.

\section{Funding/support}

This research received no specific grant from any funding agency in the public, commercial, or not-for-profit sectors.

\section{Ethics approval}

This retrospective study protocol was approved by the Institutional Review Board of the University of Hong Kong/ Hospital Authority Hong Kong West Cluster (HKU/HA HKW IRB; Ref UW 17-483) and New Territories West Cluster Clinical and Research Ethics Committee (NTWC CREC; Ref NTWC/CREC/17127). The requirement for informed consent was waived by the review board.

\section{References}

1. Boxer AL, Yu JT, Golbe LI, Litvan I, Lang AE, Höglinger GU. Advances in progressive supranuclear palsy: new diagnostic criteria, biomarkers, and therapeutic approaches. Lancet Neurol 2017;16:552-63.

2. Höglinger GU, Respondek G, Stamelou M, et al. Clinical diagnosis of progressive supranuclear palsy: The movement disorder society criteria. Mov Disord 2017;32:853-64.

3. Luk JK, Chan FH. End-of-life care for advanced dementia patients in residential care home-a Hong Kong perspective. Ann Palliat Med 2018;7:359-64.

4. Wiblin L, Lee M, Burn D. Palliative care and its emerging role in multiple system atrophy and progressive supranuclear palsy. Parkinsonism Relat Disord 2017;34:714.

5. Glasmacher SA, Leigh PN, Saha RA. Predictors of survival in progressive supranuclear palsy and multiple system atrophy: a systematic review and meta-analysis. J Neurol Neurosurg Psychiatry 2017;88:402-11.

6. Arena JE, Weigand SD, Whitwell JL, et al. Progressive supranuclear palsy: progression and survival. J Neurol 2016;263:380-9.

7. Golbe LI, Davis PH, Schoenberg BS, Duvoisin RC. Prevalence and natural history of progressive supranuclear palsy. Neurology 1988;38:1031-4.

8. Nath U, Ben-Shlomo Y, Thomson RG, Lees AJ, Burn DJ. Clinical features and natural history of progressive supranuclear palsy: a clinical cohort study. Neurology 2003;60:910-6.

9. Oliveira MC, Ling H, Lees AJ, Holton JL, De PabloFernandez E, Warner TT. Association of autonomic symptoms with disease progression and survival in progressive supranuclear palsy. J Neurol Neurosurg Psychiatry 2019;90:555-61.

10. Cosseddu M, Benussi A, Gazzina S, et al. Natural history and predictors of survival in progressive supranuclear palsy. J Neurol Sci 2017;382:105-7.

11. Chiu WZ, Kaat LD, Seelaar H, et al. Survival in progressive supranuclear palsy and frontotemporal dementia. J Neurol Neurosurg Psychiatry 2010;81:441-5.

12. Dell'Aquila C, Zoccolella S, Cardinali V, et al. Predictors of survival in a series of clinically diagnosed progressive supranuclear palsy patients. Parkinsonism Relat Disord 2013;19:980-5.

13. Santacruz P, Uttl B, Litvan I, Grafman J. Progressive supranuclear palsy: a survey of the disease course. Neurology 1998;50:1637-47.

14. Litvan I, Mangone CA, McKee A, et al. Natural history of progressive supranuclear palsy (Steele-Richardson- 
Olszewski syndrome) and clinical predictors of survival: a clinicopathological study. J Neurol Neurosurg Psychiatry 1996;60:615-20.

15. O'Sullivan SS, Massey LA, Williams DR, et al. Clinical outcomes of progressive supranuclear palsy and multiple system atrophy. Brain 2008;131:1362-72.

16. Papapetropoulos S, Gonzalez J, Mash DC. Natural history of progressive supranuclear palsy: a clinicopathologic study from a population of brain donors. Eur Neurol 2005;54:1-9.

17. Shea YF, Ha J, Chu LW. Progressive supranuclear palsy presenting initially as semantic dementia. J Am Geriatr Soc 2014;62:2459-60.

18. Chiu HF, Lee HC, Chung WS, Kwong PK. Reliability and validity of Cantonese version of the Mini-Mental State Examination: a preliminary study. J Hong Kong Col Psych 1994;4:25-8.

19. Prosser L, Canby A. Further validation of the elderly mobility scale for measurement of mobility of hospitalized elderly people. Clin Rehabil 1997;11:338-43.

20. Tomita S, Oeda T, Umemura A, et al. Impact of aspiration pneumonia on the clinical course of progressive supranuclear palsy: a retrospective cohort study. PLoS One 2015;10:e0135823.

21. Rosenbek JC, Robbins JA, Roecker EB, Coyle JL, Wood JL. A penetration-aspiration scale. Dysphagia 1996;11:93-8.

22. Edsberg LE, Black JM, Goldberg M, McNichol L, Moore L, Sieggreen M. Revised national pressure ulcer advisory panel pressure injury staging system: revised pressure injury staging system. J Wound Ostomy Continence Nurs
2016;43:585-97.

23. Testa D, Monza D, Ferrarini M, Soliveri P, Girotti F, Filippini G. Comparison of natural histories of progressive supranuclear palsy and multiple system atrophy. Neurol Sci 2001;22:247-51.

24. Diroma C, Dell'Aquila C, Fraddosio A, et al. Natural history and clinical features of progressive supranuclear palsy: a clinical study. Neurol Sci 2003;24:176-7.

25. Goetz CG, Leurgans S, Lang AE, Litvan I. Progression of gait, speech and swallowing deficits in progressive supranuclear palsy. Neurology 2003;60:917-22.

26. Jecmenica-Lukic M, Petrovic IN, Pekmezovic T, Kostic VS. Clinical outcomes of two main variants of progressive supranuclear palsy and multiple system atrophy: a prospective natural history study. J Neurol 2014;261:157583.

27. Litvan I, Kong M. Rate of decline in progressive supranuclear palsy. Mov Disord 2014;29:463-8.

28. Ou R, Liu H, Hou Y, et al. Executive dysfunction, behavioral changes and quality of life in Chinese patients with progressive supranuclear palsy. J Neurol Sci 2017;380:1826.

29. Luk JK, Chan DK. Preventing aspiration pneumonia in older people: do we have the 'know-how'? Hong Kong Med J 2014;20:421-7.

30. Lansdall CJ, Coyle-Gilchrist IT, Vázquez Rodríguez P, et al. Prognostic importance of apathy in syndromes associated with frontotemporal lobar degeneration. Neurology 2019;92:e1547-57. 